VOL. $3 \cdot 2015 \cdot$ NO. 1

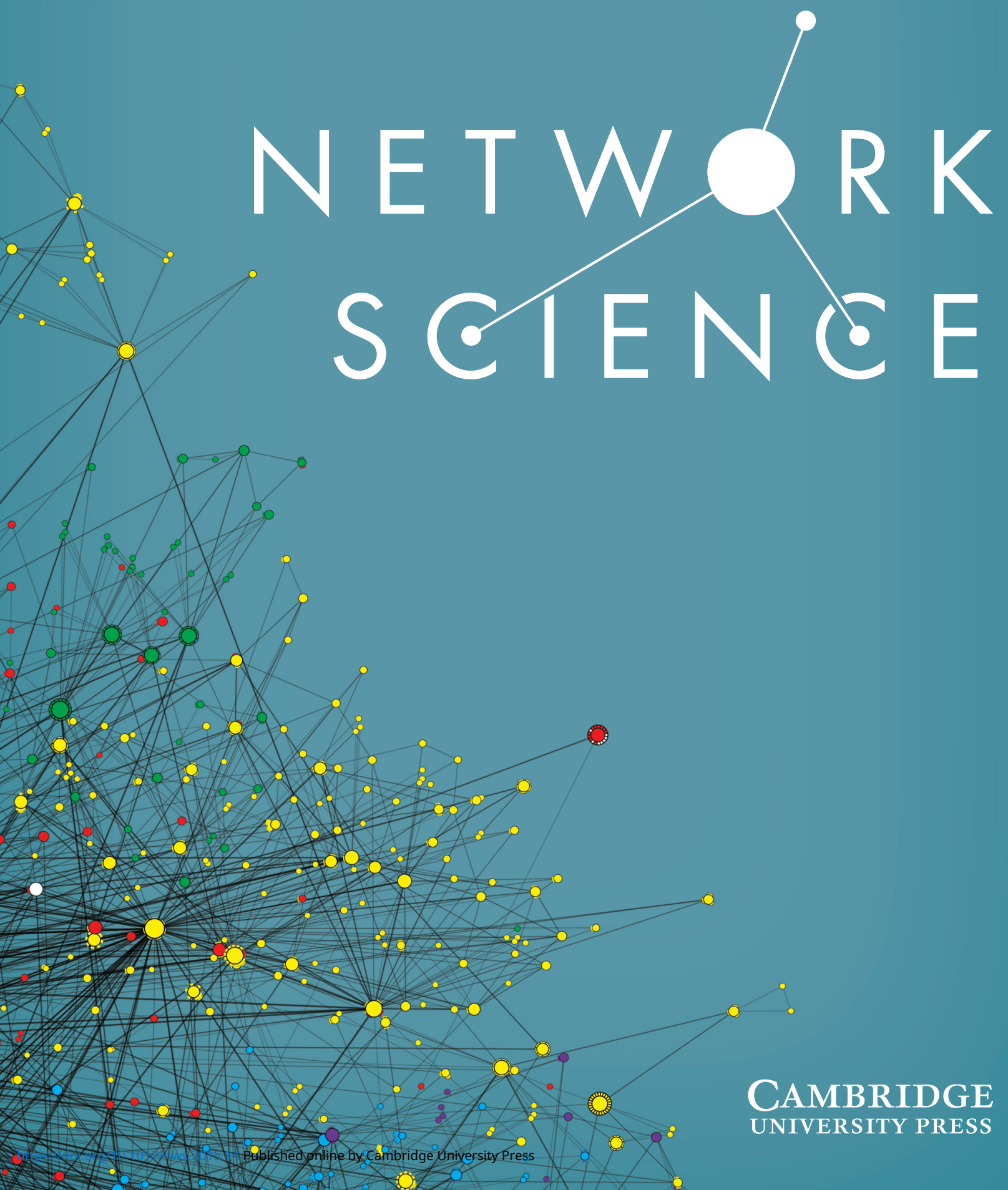




\section{Network Science Editorial Team}

EDITORS

Ulrik Brandes, Computer Science and Mathematics, University of Konstanz, Germany

Noshir Contractor, Communication, Engineering, and

Management, Northwestern University, USA

Filippo Menczer, Information Science, Indiana University, USA Garry Robins, Psychology and Political Science, University of Melbourne, Australia

Jaideep Srivastava, Web Science and Computer Engineering, University of Minnesota, USA

Thomas Valente, Public Health and Medicine, University of Southern California, USA

Fernando Vega-Redondo, Economics, Bocconi University, Italy Alessandro Vespignani, Physics, Northeastern University, USA Stanley Wasserman (Coordinating Editor), Statistics and Sociology, Indiana University, USA

\section{ASSOCIATE EDITORS}

Sinan Aral, Information Science, Management, New York University, USA

Alain Barrat, Physics, CNRS, France

Yann Bramoulle, Economics, Aix-Marseille University, France Dirk Brockmann, Computer Science, Applied Mathematics, Northwestern University, USA

Nicholas Christakis, Sociology, Medicine, Public Health, Yale University, USA

Jonathon Cummings, Business, Duke University, USA

Padraig Cunningham, Computer Science, University College Dublin, Ireland

Matthew Elliott, Economics, California Institute of Technology, USA

Christos Faloutsos, Computer Science, Data Mining,

Carnegie-Mellon University, USA

Katherine Faust, Sociology, University of California, Irvine, USA

James Fowler, Political Science, Public Health, Genetics,

University of California, San Diego, USA
Andrea Galeotti, Economics, University of Essex, UK

David Hunter, Statistics, Pennsylvania State University, USA

Yoshihisa Kashima, Psychology, University of Melbourne, Australia

Peter Key, Mathematics, Microsoft Research, UK

Laura Koehly, Psychology, Public Health, National Institutes of Health, USA

Eric Kolaczyk, Statistics, Boston University, USA

David Krackhardt, Public Policy, Business, Carnegie-Mellon

University, USA

David Lazer, Information Science, Political Science, Northeastern University, USA

Roger Leenders, Business, Organization Studies, Tilburg

University, Netherlands

Kristina Lerman, Computer Science, ISI and University of Southern California, USA

Mark Lubell, Political Science, Environmental Policy, University of California, Davis, USA

Winter Mason, Psychology, Cognitive Science, Stevens Institute, USA James Moody, Sociology, Duke University, USA

Sue Moon, Computer Science, Korea Advanced Institute of Science and Technology, Republic of Korea

Romualdo Pastor-Satorras, Mathematics, Physics, Polytechnic

University of Catalunia, Spain

Bernice Pescosolido, Sociology, Indiana University, USA

Richard Rothenberg, Public Health, Epidemiology, Georgia

State University, USA

Olaf Sporns, Psychology, Neuroscience, Indiana University, USA

Douglas Steinley, Psychology, Statistics, University of Missouri, USA Adam Szeidl, Economics, Central European University, Hungary

Zoltan Toroczkai, Physics, University of Notre Dame, USA

Marco van der Leij, Economics, University of Amsterdam, Netherlands

MANAGING EDITOR

Ann McCranie, Sociology, Indiana University, USA

\section{Network Science}

Network Science is a new journal for a new discipline - one using the network paradigm, focusing on actors and relational linkages, to inform research, methodology, and applications from many fields across the natural, social, engineering and informational sciences. Given growing understanding of the interconnectedness and globalization of the world, network methods are an increasingly recognized way to research aspects of modern society along with the individuals, organizations, and other actors within it.

The discipline is ready for a comprehensive journal, open to papers from all relevant areas. Network Science is a defining work, shaping this new discipline. The journal welcomes contributions from researchers in all areas working on network theory, methods, and data.

SUBSCRIPTION INFORMATION

Network Science (ISSN: 2050-1242) is published four times per year, in March, June, September, and December by Cambridge University Press, 32 Avenue of the Americas, New York, NY 10013, USA.

The subscription price of Volume 3 (2015) including delivery by air where appropriate (but excluding VAT), is \$638.00 (£399.00) for institutions print and online; $\$ 605.00$ ( $£ 378.00$ ) for institutions online only.

Orders, which must be accompanied by payment, may be sent to a bookseller, subscription agent or direct to the publisher: Cambridge University Press, Journals Fulfillment Department, 100 Brook Hill Drive, West Nyack, NY 10994-2133, USA; or Cambridge University Press, The Edinburgh Building, Shaftesbury Road, Cambridge CB2 8RU, England. Alternatively, you can place an order online at <journals.cambridge.org/nws $>$.

For single issues, please contact customer_service@cambridge.org.

ADVERTISING

For information on display ad sizes, rates, and deadlines for copy, please visit the journal homepage at $<$ journals.cambridge.org/nws $>$ or contact ad_sales_cambridge.org.

INTERNET ACCESS

Network Science is included in the Cambridge Journals Online service, which can be accessed at <journals.cambridge.org $>$. For information on other Cambridge titles, visit <www.cambridge.org $>$.

ISSN: $2050-1242$

EISSN: $2050-1250$

Copyright (C) Cambridge University Press 2015. All rights reserved. No part of this publication may be reproduced, in any form or by any means, electronic, photocopying, or otherwise, without permission in writing from Cambridge University Press. Policies, request forms and contacts are available at: http://journals.cambridge.org/action/rightsAndPermissions

Permission to copy (for users in the U.S.A.) is available from Copyright Clearance Center http://www.copyright.com, email: info@ copyright.com. Postmaster: Send address changes to Network Science, Cambridge University Press, 100 Brook Hill Drive, West Nyack, NY 10994-2133, USA. 


\title{
NETWORK SCIENCE
}

Volume 3

Number 1

\author{
Special Issue on Networks in Space and in Time: Methods and Applications
} edited by Luca De Benedictis, Maria Prosperina Vitale, and Stanley Wasserman

\section{CONTENTS}

\author{
Articles \\ Examining the literature on "Networks in Space and in Time." An introduction \\ LUCA DE BENEDICTIS, MARIA PROSPERINA VITALE AND STANLEY WASSERMAN
}

Multiple factor analysis for time-varying two-mode networks

GIANCARLO RAGOZINI, DOMENICO DE STEFANO AND MARIA ROSARIA D'ESPOSITO

Factorial graphical models for dynamic networks

ERNST WIT AND ANTONINO ABBRUZZO

Simultaneous modeling of initial conditions and time heterogeneity in dynamic networks: An application to Foreign Direct Investments

JOHAN KOSKINEN, ALBERTO CAIMO AND ALESSANDRO LOMI

Comparing membership interest group networks across space and time, size, issue and industry

JANET M. BOX-STEFFENSMEIER AND DINO P. CHRISTENSON

Static and dynamic networks in interbank markets

ETHAN COHEN-COLE, ELEONORA PATACCHINI AND YVES ZENOU

Space, time, and the development of shared leadership networks in multiteam systems

SOPHIA D. SULLIVAN, ALINA LUNGEANU, LESLIE A. DECHURCH AND

NOSHIR S. CONTRACTOR

A spatial multi-scale object to analyze road networks

C. LAGESSE, P. BORDIN AND S. DOUADY 